\title{
Design Research on Hydraulic System of Working Device of a Forklift
}

\author{
Liai $\operatorname{Pan}^{1, a}$, Qiulei $\mathrm{Du}^{2, \mathrm{~b},{ }^{*}}$ and Chunshan $\mathrm{He}^{3, \mathrm{c}}$ \\ ${ }^{1,3}$ College of Mechanical and Vehicle Engineering Changchun University, Changchun, China \\ ${ }^{2}$ College of Special Education Changchun University,Changchun, China \\ aemail:panli636@126.com, bemail: apriljuan@hotmail.com, email: he03cs@126.com
}

Keywords: Working Device, Hydraulic System, Forklift, Design.

Abstract. As a kind of industrial handling vehicles, forklift plays an indispensable role in people's life. Nowadays, in order to meet the needs of the people, the types of forklift are more and more. In this paper, based on already the basic parameters of the push forward forklift in the market, the working device of the forklift has been introduced. And according to the calculation and checking, the main structural parameters of the lifting oil cylinder have been determined. The hydraulic system has been designed and calculated. The results of the paper have important practical significance to design of work device of the forklift.

\section{Introduction}

Forklift is an industrial power truck used for lifting and transport materials. Through the steel fork under the load, the lifting and transportation have been done. At present, different kinds of forklift are many. According to the lifting weight of forklift, forklift is divided into small tonnage $(0.5 \mathrm{t})$ and $1 \mathrm{t}$, middle tonnage ( $2 \mathrm{t}$ and $3 \mathrm{t}$ ) and large tonnage ( $5 \mathrm{t}$ and above). According to the location relationship between the goods and the forklift, the forklift is divided into positive and side forklift. And the working device of the forklift is a very important part of the forklift. In this paper, the working device of the forklift has been to designed and the hydraulic system of the door frame have been calculated. $[1-3]$

\section{Design of working device}

The working device is an important part of the forklift. When the forklift is loading and unloading handling, it is directly under all the cargo weight and finished the goods fork, handling, lifting, etc. It is mainly composed of the door frame, outrigger and cargo, guide wheel, the chain, and lifting oil cylinder, etc[4,5].

\section{Door Frame}

On both sides of the door frame, the channel steel has been used as a whole stent, and has been welded into the frame type, then on the basis, the corresponding structure has been welded. But because the forklift was balance type, the structure of the door frame has been corresponding changed to adapt the demand of the balance weight forklift. The overall structure has been shown in figure 1 .

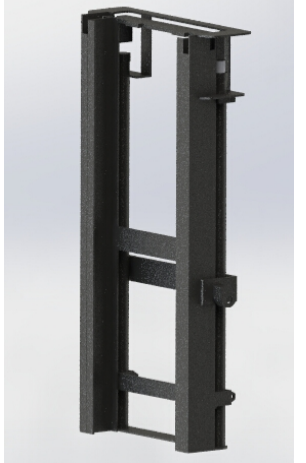

Fig.1 Door Frame

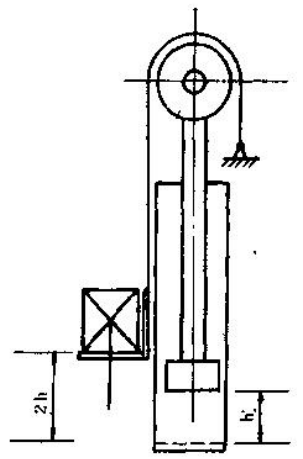

Fig.2 Schematic diagram of the Lifting mechanism transmission 


\section{Lifting Mechanism}

The lifting mechanism of the forklift is composed of lifting oil cylinder, lifting chain, guide pulley and roller frame, etc.

(1) The movement of the lifting mechanism

The lifting mechanism has been shown in figure 2. The front end of the lifting chain was connected to the outrigger, the middle was around the guide pulley, the back end was fixed on the beams of the door frame, and the guide pulley was installed to the guide roller frame in the upper part of the piston rod. So it was made a block and tackle. When hydraulic push upward movement of the piston rod $1 \mathrm{~h}$, fork rose $2 \mathrm{~h}$.

(2) The function and structure of the guide pulley and the lifting chain

Guide roller is mainly used for support and guidance of the lifting chain. In the lifting chain driving, it can rotate around the axis. Because of chain is different, its structure is different also.

The functions of the lifting chain are supporting the quality of the outrigger and the goods, and driving the flexible parts of the outrigger lift. Commonly the plate chain and sleeve roller chain have been used. The lifting chain of the prototype forklift is the sleeve roller chain, here keep unchanged.

\section{Cargo Fork}

Fork length associated with lifting weight. China's first machinery industry department issued by the equilibrium weight 0.55 tons of internal combustion type forklift to fork length and loading in the standard center distance made rules, such as shown in table 1.

Table.1 Relationship of Forklift rated lifting weight, load center distance and fork length

\begin{tabular}{|c|c|c|c|c|c|}
\hline Rated lifting weight,Q(ton) & 0.5 & 1 & 2 & 3 & 5 \\
\hline Load center distance,C(mm) & 400 & 500 & 500 & 500 & 600 \\
\hline Fork length,1(mm) & 700 & 900 & 900 & 1000 & 1200 \\
\hline
\end{tabular}

In the paper, the lifting weight of the forklift was 3 tons. Control chart, the fork length of the weight of the 3 tons can be choose, was $1000 \mathrm{~mm}$; and according to the thickness of cargo fork cross section size table and the thickness of the prototype forklift pallet fork to select, the thickness of the cargo fork was $45 \mathrm{~mm}$, the width of cargo fork was took to the original $125 \mathrm{~mm}$.

\section{Design of the Hydraulic System of Working Device}

\section{Design Overview of the Hydraulic System}

Forklift truck working device hydraulic system includes a tilt lifting oil cylinder and the cylinder. The lifting oil cylinder can lift the goods. The tilting cylinder can make before and after loading framework tilt, to facilitate handling and walking, and easy to use.

The oil pump output pressure oil into the working device and steering mechanism respectively. By tilting the handle make multiple directional control valves before and after the slide valve movement to change the hydraulic oil flow direction, so as to control the lifting oil cylinder and door frame tilting cylinder, and before and after the realization of lifting shelf and door frame. Another oil is that the oil by the steering pump and motor inflows to the full hydraulic steering gear to control oil cylinder; finally, the oil will be returned to the oil tank and such a cycle. Hydraulic system is an important link of the working process of the forklift. A reasonable hydraulic system scheme can achieve the host requirements of various functions, and convenient manipulation, reliable operation, smooth motion, convenient adjustment and maintenance. [6]

\section{Principle of the Hydraulic System}

Design description of the hydraulic system:

(1) Tank: open tank.

(2) Hydraulic pump: the gear pump has been adopted as working oil pump, models for CB - F18C FL.

(3) Working motor: Z4-112-4.

(4) Lifting oil cylinder: single-acting piston hydraulic cylinder.

(5) Tilting cylinder: double-acting piston hydraulic cylinder. 
(6) Hydraulic control valve: multiple directional control valves ZFS-L10C-YT-O.

(7) The speed limit flow control: a one-way valve.

(8) Auxiliary hydraulic parts design: design of filter, air filter design, various kinds of instrument choice selection of seal, hydraulic oil and pressure loss calculation.

The principle diagram of hydraulic system has been shown in figure 3 .

\section{Maximum Working Pressure and Flow Rate of the Lifting Oil Cylinder}

The pressure was $100 \mathrm{~kg} / \mathrm{cm}^{2}$; the flow rate was $25.8 \mathrm{~L} / \mathrm{min}$

\section{Maximum Pressure of the Hydraulic System}

Maximum pressure of the reversing valve requirement was $140 \mathrm{~kg} / \mathrm{cm}^{2}$, with reference to the similar products, $\mathrm{P}_{1}$ has been chose $100 \mathrm{~kg} / \mathrm{cm}^{2}$.

\section{Pump Power and Motor Selection}

(1) The drive power of the pump:

$$
P=\frac{P_{p}+Q_{n}}{61.2 \times \eta_{v}} w
$$

In the formula, $\mathrm{P}_{\mathrm{p}}$ was the actual maximum working pressure of the pump, taking $140 \mathrm{MPa}$; Qn was the rated flow of pump, taking $510 \mathrm{~cm}^{3} / \mathrm{s} ; \eta_{v}$ was the mechanical efficiency of the pump, taking 0.8 .

So, $\quad P=\frac{14 \times 10^{6}+510 \times 10^{6}}{61.2 \times 0.8}=8925 \mathrm{~W}=8.93 \mathrm{~kW}$.

(2) The choice of the oil pump motor

According to the oil pump rated speed and power needed to drive, the Z4-112-4 has been selected. Its parameters are as follows that rated power of $5.5 \mathrm{~kW}$, rated voltage of $160 \mathrm{~V}$, rated current of 42.7 A, speed (highest) 3000/4000 r/min, efficiency of $83.5 \%$, the flywheel moment of 0.8 , quality of $60 \mathrm{~kg}$. The oil pump motor what chose adopts 5 min work week. So, after converted into power, $P=5.5 \times \sqrt{\frac{15}{5}}=9.5 \mathrm{~kW}$, the oil pump motor was appropriate to work.

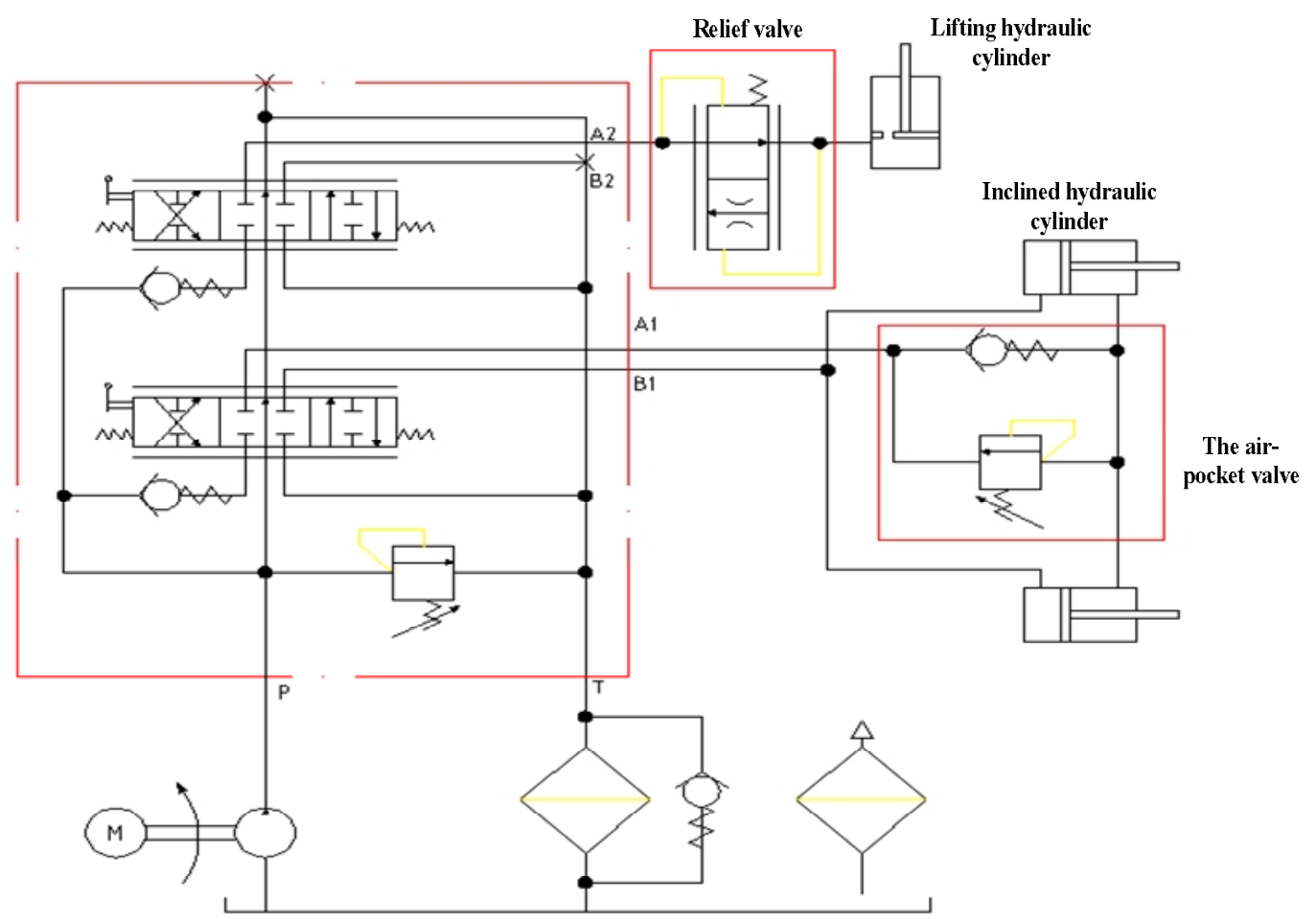

Fig. 3 Principle of the hydraulic system 


\section{Design Calculation of the Tubing}

(1) Pressure tubing

Diameter of the tubing:

In the formula, $\mathrm{d}$ was Diameter of the tubing, mm; Q was the flow of the tubing, taking $30 \mathrm{~L} / \mathrm{min}$; $\mathrm{v}$ was the velocity in the tubing, $\mathrm{m} / \mathrm{s}$.

Checking the hydraulic system design manual "on page 864 , according to the oil mouth nominal diameter size: $\mathrm{d}=15 \mathrm{~mm}$, outside diameter was $22 \mathrm{~mm}$ corresponding pipe thread for M22 $\times_{1.5}$.

(2) Velocity in the tubing

$$
V=\frac{4 Q}{\pi d^{2}}=\frac{4 \times 30}{3.14 \times 0.15^{2}}=1.69 \mathrm{~m} / \mathrm{min}
$$

Meet the requirements.

(3) Wall thickness of the tubing

$$
\delta=\frac{P d}{2[\sigma]} \mathrm{cm}=\frac{168 \times 6.3}{2 \times 800}=0.66 \mathrm{~cm}
$$

In the formula, $P$ was maximum working pressure of hydraulic system, taking $140 \mathrm{~kg} / \mathrm{cm}^{2} ; \mathrm{d}$ was cylinder bore, $\mathrm{mm} ;[\sigma]$ was the allowable tensile stress, $\mathrm{kg} / \mathrm{cm}^{2}$, for steel tube $[\sigma]=\frac{\sigma_{b}}{n}$, taking $\sigma_{b}=6000 \mathrm{~kg} / \mathrm{cm}^{2}$. Checking the hydraulic control driving manual, when $\mathrm{P}<7.5 \mathrm{MPa}$, the safety coefficient $\mathrm{n}=8$; when $\mathrm{P}=7.5 \sim 17.5 \mathrm{MPa}$, the safety coefficient $\mathrm{n}=4$; so, $[\sigma]=\frac{6000}{6}=1000 \mathrm{~kg} / \mathrm{cm}^{2}$, the wall thickness what the tubing has been chose was shown in type $\delta=\frac{140 \times 15}{2 \times 1000} \mathrm{~mm}=1.05 \mathrm{~mm}$ [7].

Considering the connection of the coupling and valve parts, taking $\delta=3 \mathrm{~mm}$. The diameter of steel pipe $=15+2 \times 3=21 \mathrm{~mm}$, the steel pipe what been chose $\operatorname{was} \varphi 20 \times 3$.

(4) Return line selection: in order to ensure the uniformity, the same as the pressure tubing chose.

\section{Conclusion}

With the development of the logistics warehousing, industrial vehicle products to enter the workshop, warehouse, supermarket and so on. As a kind of industrial vehicles, the current types of forklift are limited, it can't completely adapt to a variety of occasions. Most of the time, standard forklifts are only suitable for a particular occasion, in addition to these specific occasions; they may not very effective role. In this paper, based on already the basic parameters of the push forward forklift in the market, the working device of the forklift has been introduced. And according to the calculation and checking, the main structural parameters of the lifting oil cylinder have been determined. The results of the study have an important practical significance on meeting people's specific needs and improving the work efficiency, etc.

\section{References}

[1] Engyi Su, Present Situation and Development of the Light Small Carrying Vehicles, J. Logistics technology and application. 3(2003) 25-27.

[2] Qijun Zhang, Technology Development Trend of Foreign Forklift, J. Construction machinery technology and management. 12(1999) 36-38. 
[3] Yuanfang Tao, Design and Development Trend of Forklift, J. Forklift technology. 4(1995) 10-12.

[4] Yuanfang Tao. Liangbao Wei, Construction and Design of Forklift. Mechanical industry press, Beijing, 2010.

[5] Zhi Luo, Design of Forklift, Mechanical industry press, Beijing, 1991.

[6] Peiyuan Yang. Fuyuan Zhu, Concise manual of hydraulic system design, Mechanical industry press, Beijing, 2011.

[7] Qisong Chen, Hydraulic transmission and control manual, Shanghai science and technology publishing company, Shanghai, 2006. 